\title{
Decision Support System for the Provision of Emergency Sanitation
}

\author{
F. Zakaria*, H.A. Garcia*, C.M. Hooijmans* and D. Brdjanovic*,**
}

\author{
* Department of Environmental Engineering and Water Technology, UNESCO-IHE, Westvest \\ 7, 2611 AX, Delft, Netherlands \\ (E-mail: f.zakaria@unesco-ihe.org; fionazakaria@gmail.com) \\ ** Faculty of Applied Sciences, Department of Biotechnology, Delft University of Technology, \\ Julianalaan 67, 2628 BC Delft, The Netherlands)
}

\begin{abstract}
Proper provision of sanitation in emergencies is considered a life-saving intervention. Without access to sanitation, refugees at emergency camps are at a high risk of contracting diseases. Even the most knowledgeable relief agencies have experienced difficulties providing sanitation alternatives in such challenging scenarios. This study developed a computer-based decision support system (DSS) to plan a sanitation response in emergencies. The sanitation alternatives suggested by the DSS are based on a sanitation chain concept that considers different steps in the faecal sludge management, from the toilet or latrine to the safe disposal of faecal matters. The DSS first screens individual sanitation technologies using the user's given input. Remaining sanitation options are then built into a feasible sanitation chain. Subsequently, each technology in the chain is evaluated on a scoring system. Different sanitation chains can later be ranked based on the total evaluation scores. The DSS addresses several deficiencies encountered in the provision of sanitation in emergencies including: the application of standard practices and intuition, the omission of site specific conditions, the limited knowledge exhibited by emergency planners, and the provision of sanitation focused exclusively on the collection step (i.e., just the provision of toilets).
\end{abstract}

Keywords: Decision support system; sanitation technologies; sanitation chain; emergency sanitation; disasters

\section{Introduction}

This study describes a computer-based decision support system (DSS) developed for selecting the most suitable sanitation alternative for emergency situations. The sanitation alternatives suggested by the DSS were defined considering a sanitation chain approach (that is, each sanitation alternative includes excreta disposal, collection, conveyance, treatment, and final disposal or reuse). The computer-based DSS will contribute to ensuring a sustainably operated and maintained sanitation response in emergencies.

Natural and anthropological disasters may lead to the displacement of large numbers of people into temporary settlements or camps. The temporary camps are often overcrowded and contain rudimentary shelters, inadequate safe water and sanitation provision, and a high potential exposure of people (camp residents) to disease vectors. The majority of diseases causing mortality and morbidity in displacement camps (e.g., cholera, diarrhoea, worms, skin irritation, and eye-irritation, among others) have a strong correlation with the state of the sanitation provision at the camps. Without a proper sanitation provision, people living in the displacement camps are at a high risk of contracting diseases.

The word 'sanitation', as well as 'environmental sanitation' could be broadly defined to 
refer to maintenance hygienic state of certain living environments. This translates into range of activities such as human excreta disposal, household wastewater disposal, vector control as well as solid waste management. However, in the context of emergency where the humanitarian aim is to meet basic sanitation and where the major concern is disease preventions, the word 'sanitation' is considered to have the strongest ties with human excreta disposal and management. Thus for this reason, this study discusses 'sanitation' as excreta disposal management.

The emergency sanitation provision at the emergency camps is predominantly decided by the site planners, which are the corresponding relief agencies together with the local governmental authorities. Due to the many constraints present in an emergency situation, the most commonly selected sanitation alternative has been the simplest possible alternative, limited to onsite decentralized systems, with excavated latrines such as pit latrines or trench latrines being the most popular choice. These basic sanitation alternatives often fail exacerbating even more the problems already encountered in an emergency setting. Failures are due to unstable soils, high water tables, flood-prone areas, locations in which it is not possible to excavate (due to rocky ground conditions, space limitation, and/or land ownership), among others. Such complex emergency scenarios require the provision of sanitation alternatives beyond the old fashioned and problematic latrine, so there is a current need to innovate in the provision of sanitation services considering the complexity commonly observed in emergency situations (Johannessen et al., 2012).

After a massive earthquake which caused catastrophic damages in Haiti in 2010, several sanitation alternatives were evaluated, including biodegradable bags (such as peepoo-bags), biogas domes, composting latrines, urine-diversion technologies, raised latrines, several prefabricated latrines (using diverse materials), and pit lining alternatives to overcome problems of collapsing pits. The majority of these systems were modifications of existing technologies developed for a non-emergency context; however, these alternatives still added some novelty to the field. The performance of these sanitation alternatives was not as satisfactory as expected. As an example, even though the raised latrines were generally well accepted as the best solution for many emergency settlements in Haiti (considering it was impossible to dig pits for latrines), some problems were encountered with this system. The raised latrines were availed and initially maintained by the relief agencies present in Haiti. They required periodical tank emptying to sustain their operation. Once the relief agencies in charge ran out of budget, the latrines were abandoned without a proper closure strategy plan in place (Manilla Arroyo, 2014). Several over-spilling latrines were observed. At the time of the cholera outbreak this issue was clearly a major concern. Therefore, the incorporation of sanitation alternatives in an emergency setting without foreseeing the management plan may not result in a sustainable sanitation provision.

The constraints of time and resources placed on the site planners during the planning of the sanitation provision during an emergency situation usually may lead to the use of standard remedies and not optimum solutions (Fenner et al., 2007). The lessons learned from previous emergencies situations are not well communicated. That is, the knowledge is kept within the particular relief agencies and/or local authorities. Therefore, site planners often have limited knowledge on the variety of possible sanitation technologies that can be provided leading to unawareness regarding the best possible solution (Mara et al., 2007).

\subsection{Sanitation Chain Concept}

The sanitation provision should be perceived beyond the provision of just toilets or latrines (Sparkman, 2012; Verhagen and Ryan, 2008), aiming at achieving an overall improvement on public health. The provision of toilets or latrines should be the first step of a series of 
steps/processes involved in the provision of a complete and solid sanitation alternative. These

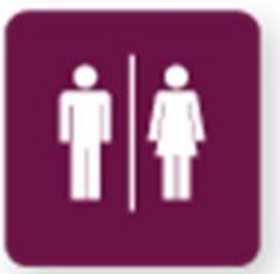

Production

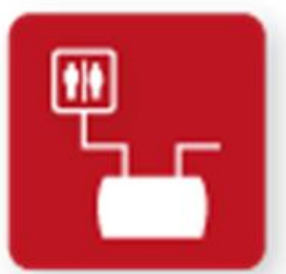

Capture

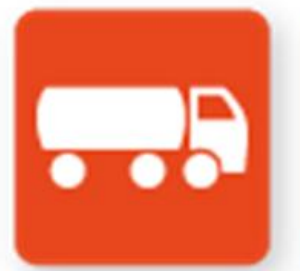

Collection \& Transport

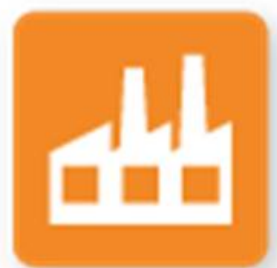

Treatment or Disposal

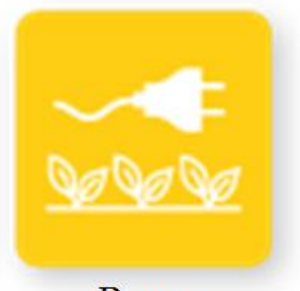

Reuse

Figure 1. Sanitation chain system (modified from Wirmer (2014))

\subsection{Review of Available Sanitation Decision Support System}

A decision-making support tool is defined as a product that combines information on a user's given situation with information on available technologies and approaches helping the practitioners to select the best available technology or approach (Palaniappan et al., 2008). An accurate DSS will contribute to tackling several of the deficiencies currently observed in the provision of sanitation services in emergencies including: (i) the application of standard practices and intuition from the relief planners in the selection of a particular sanitation option, (ii) the omission of the complex scenarios commonly found in emergency settings, (iii) limited knowledge shown by site planners, and (iv) the misconception that sanitation provision can be achieved by just providing toilets without considering the provision of a whole sanitation chain.

Various support tools have been developed to assist with the selection of the most appropriate sanitation options. SANCHIS (Buuren, 2010) recommended the use of a 
participatory multi-criteria analysis (MCA) to select the most appropriate technology for MCA for basic sanitation was proposed by Garfi and Ferrer-Marti (2011). Similarly, Katukiza et al., (2010) combined the use of expert opinions with a participatory processes to select most suitable sanitation options in urban slum settings. Tilley et al., (2010) described and classified different sanitation technologies to facilitate an educated decision-making sanitation provision process. All of these support systems were developed for non-emergency settings; that is, the complex scenarios commonly introduced by emergency situations were not considered.

Computer programs have been developed in an attempt to facilitate the complex decision-making process for the selection of the most appropriate sanitation option. Some of these computer programs include WAWTTAR (Finney and Gerheart, 1998), SANEX ${ }^{\text {TM }}$ (Loetscher and Keller, 2002), and SETNAWWAT (Sah et al., 2010). All of them were designed to be applied in a development (non-emergency) context; therefore, they will not be that accurate when dealing with emergency scenarios.

Some DSS were indeed developed considering the emergency context. They are presented in the form of standard document (e.g., SPHERE standard (Sphere, 2004)), technical briefs (e.g., Reed (2010)), technical books (e.g., Harvey et al. (2007); Wisner (2002); and Burnham et al.(2004)), decision trees (e.g., Fenner et al. (2007); Reed (2010); and UNHCR (1999)), and matrices. Most of these decision support tools do not incorporate key aspects when dealing with the provision of sanitation services in emergencies such as universality, inclusion of the latest developments on technologies, and user-friendly interfaces. In addition, none of these DSS are offered in a computer program format. Akvo-WASTE Netherlands (Akvo.org and WASTE, 2012; Castellano et al., 2011) has recently expanded an online tool that provides users with some specific selection criteria including a preliminary description of sanitation technologies considering the emergency situation context. Even though this tool incorporates computer programming and the emergency context considerations, the tool cannot be considered as a complete DSS at its current stage.

Therefore, there is a need for developing an emergency sanitation DSS in the form of a computer program considering the complex scenarios commonly found in emergency settings. In addition, an accurate DSS should incorporate the provision of a sanitation chain rather than a single sanitation technology. It should serve as an interactive, practical, as well as userfriendly decision-making tool facilitating the selection of the best sanitation option considering the emergency context. These issues were explored in this study leading to a DSS tool described in this paper.

\section{Methodology}

This research was conducted in the following phases: (i) selection of sanitation technologies to be included in the emergency sanitation DSS; (ii) definition of criteria and selection processes; (iii) development of the DSS conceptual framework; and (iv) computer programming.

\subsection{Selection of sanitation technologies to be included in the emergency sanitation DSS}

The sanitation technologies included in the selection process are proven technologies that have been used in previous emergencies, or technologies that have a potential to be used in future emergencies. The selected technologies are further classified considering the steps of the sanitation chain concept previously described and presented in Figure 1. A specific sanitation chain was defined for this study consisting of the following steps: (i) user interface, 
(ii) collection, (iii) conveyance, (iv) semi-centralized 1, (v) semi-centralized 2, and (vi) disposal/reuse. The classification of the individual sanitation technologies in the different steps of the sanitation chain are presented in Table 1. The technology definitions are mostly based on the Compendium of Sanitation Systems and Technologies by Tilley et al. (2014), but certain technologies descriptions that were not included in the compendium are taken from other sources, being mainly reports from relief agencies.

\subsection{Definition of criteria and selection processes}

Various criteria that affect the selection of sanitation technologies were defined. These criteria are technology-specific, site-specific, and socio-culture-specific. Furthermore, the criteria were classified based on how they interfere in the selection process. There are some criteria that eliminate sanitation technologies when the conditions set by the criteria are not met (screening criteria). Other criteria evaluate the suitability of the sanitation technologies to the given scenario (evaluation criteria) by assigning a certain score to each sanitation technology for each defined criterion.

Not all the sanitation technology options at each step of the sanitation chain are compatible. Therefore, additional considerations were incorporated to determine whether a sanitation technology in a particular step of the sanitation chain could work in combination with the sanitation technologies proposed for the rest of the sanitation chain. The compatibility of each sanitation option was then mapped in a matrix specially designed for evaluating compatibility issues of the different sanitation technologies. The compatibility of one sanitation option to another is assessed and given binary value to express whether the pair is compatible or not. The values were based on information obtained from the literature, as well as from the authors' own interpretation.

\subsection{Development of the DSS conceptual framework}

The information flow for the developed DSS is described in Figure 2. All the sanitation options go first through an initial screening process. The screening process evaluates all the sanitation options considering the predefined screening criteria and incorporating all the inputs introduced by the users. The screening process results in all the feasible sanitation options for a particular emergency scenario. The users would then be asked to build a sanitation chain combining the feasible options. The sanitation chain would further be evaluated using the subsequent evaluation criteria (incorporating again the users' inputs) resulting in the most suitable sanitation option (in the form of a sanitation chain) for a particular emergency scenario. The evaluation stage is particularly useful for the users to be able to identify the potential advantages and limitations of their chosen sanitation options. The evaluation stage requires the users to score each option to provide basis of quantifying the quality of each option that the users can compare them with other options. 


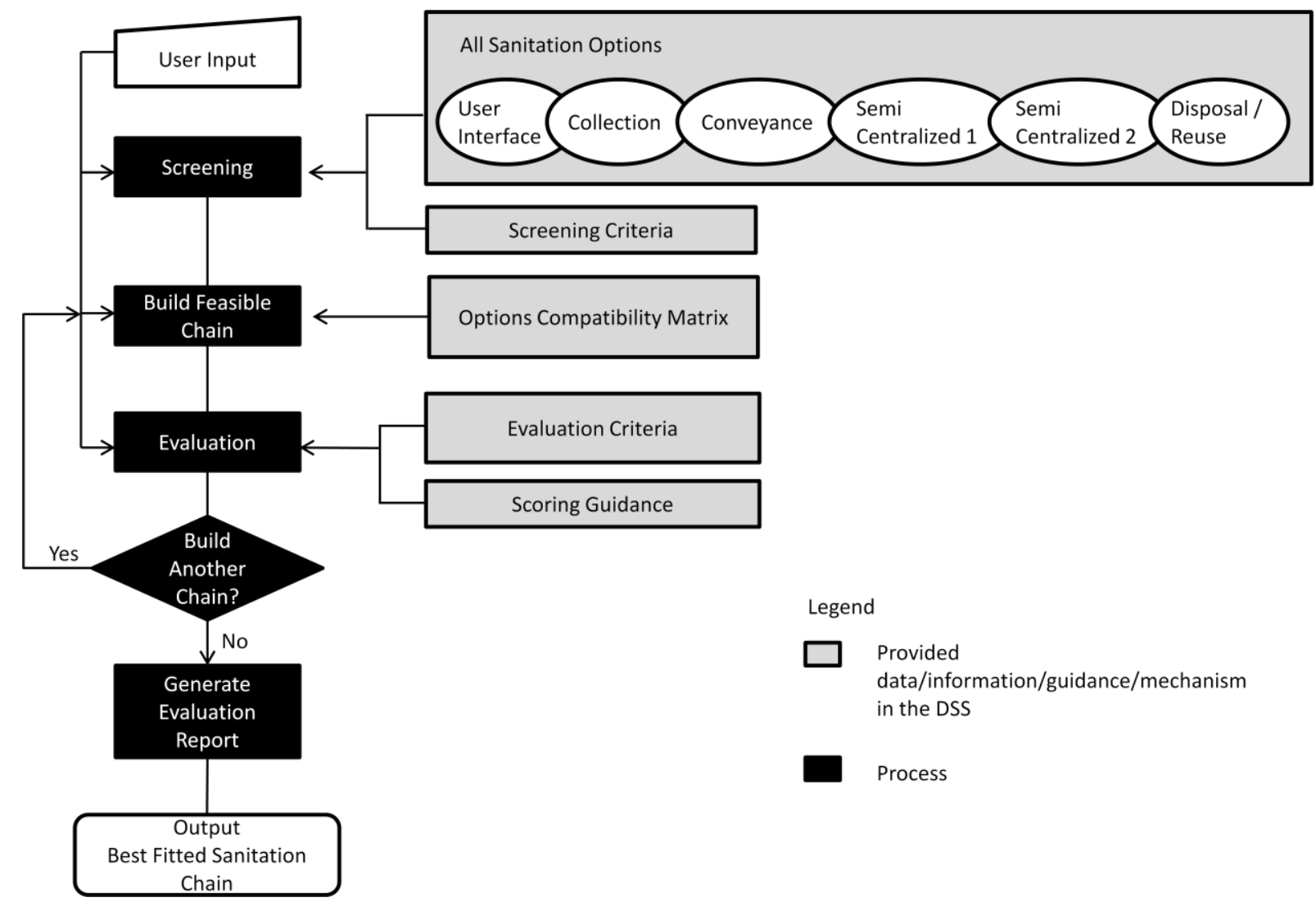

Figure 2. Decision support system information flow

\subsection{Computer programming}

The computer-based DSS was developed using Visual Basic for Applications (VBA) Version 6 in Microsoft Office Excel 2007 (32-bit version). The software is user-friendly, so the DSS can be executed without the need for specific training. The DSS was designed to operate off-line, so it can be applied without the need of being connected to the internet. The DSS programme will be downloadable on-line from a specific website.

\section{Results and Discussion}

The results section of this study presents the computer-based DSS. First the selected suitable sanitation technologies included in the DSS are described. Each selected technology is further classified following the specific components of the sanitation chain. Next, the factors influencing the suitability of all the potential sanitation technologies in the decision-making process are identified; they are presented as selection criteria (either screening, or evaluation criteria). Subsequently, the logic followed for conducting the screening and evaluation stages is presented. Finally, the computer-based DSS is evaluated comparing the DSS recommendations with the sanitation provision observed in Haiti after the earthquake in 2010.

\subsection{Selection of sanitation technologies included in the emergency sanitation DSS}

The sanitation technologies further classified in the single components of the sanitation chain are presented in Table 1. 
Table 1

Sanitation technologies included in the emergency sanitation DSS (classified in the individual components of the sanitation chain)

\begin{tabular}{ll}
$\begin{array}{c}\text { Chain } \\
\text { components }\end{array}$ & \multicolumn{1}{c}{ Technologies } \\
\hline (1) User Interface & $\begin{array}{l}\text { (101) No User Interface; (102) Drop Hole; (103) } \\
\text { Pour Flush; (104) Urine Diversion; and (105) Urinal }\end{array}$ \\
& \\
& \\
(2) Collection & (201) Biodegradable Bags; (202) Buckets; (203) \\
& Controlled Open Defecation; (204) Shallow Trench \\
& Latrines; (205) Deep Trench Latrines; (206) \\
& Borehole Latrines; (207) Simple Pit Latrines; (208) \\
& Ventilated Improved Pit Latrines; (209) Arborloo; \\
& (210) Fossa Alterna; (211) Porta Preta; (212) Septic \\
& Tank; (213) Aerobic Filtration (AF); (214) \\
& Anaerobic Batch Reactor (ABR); (215) Aqua \\
& Privies; (216) Urine Diversion Dehydrated Toilet \\
& (UDDT); (217) Urine Diversion Toilet (UDT); (218) \\
& Floating Latrines; (219) Raised Latrines; (220) \\
& Urine Jerrycan Storage; and (221) Chemical Toilet.
\end{tabular}

(3) Conveyance

(4) Semi

Centralised 1

(5) Semi

Centralised 2

(6) Disposal and Reuse
(301) No Emptying/Collection and Transport; (302)

Human Powered Emptying/Collection and

Transport; (303) Human Powered

Emptying/Collection and Motorised Transport;

(304) Motorised Emptying and Manual Transport;

(305) Motorised Emptying and Transport; and (306)

Sewerage

(401) No Treatment; (402) Co-composting; (403)

Planted Drying Beds; (404) Unplanted Drying Beds; (405) Sedimentation/Thickening; (406) Waste Stabilisation Pond (WSP); (407) Surface Flow Constructed Wetlands.

(501) No Treatment; (502) Trickling Filters; (503)

Upflow Anaerobic Sludge Blanket (UASB); (504)

Membrane Bioreactor (MBR); and (505)

Conventional Activated Sludge (CAS)

(601) Urine Fertilizer; (602) Sludge/Dried Faecal

Matter Fertilizer; (603) Burying/Fill and Cover

Onsite; (604) Burying/Fill Cover Offsite; and (605)

Surface Disposal/Open Dumping

\begin{abstract}
Considering that water supply and
energy are usually insufficient in addition to unavailability of piped water in emergencies. Cistern and mechanics flushed interfaces are not considered
\end{abstract}

All options are operated without energy requirements

Conveyance includes

collection/emptying and transport. Both process technologies can be classified into manual or motorised; thus, the technical options are either manual, motorized, or a combination of the two.

Most of them are primary treatment options that can receive highly concentrated faecal sludge, stand alone operated treatment units. They can also act as pre-treatment system for Semi-Centralised 2

Treatment options that works in combination with Semi-Centralised 1 systems, or are fed by means of a sewerage system

Feasible options with regard to emergencies. Nutrient recovery reuse options are also included

To promote a better understanding of the different sanitation technologies, each option is linked to a pop-up window in the computer program DSS containing brief information of the technology as shown in Figure 3. The information includes a general basic description of the technology, advantages, limitations, the applicability of this technology in an emergency situation, and its classification in the sanitation chain. The technology descriptions were taken from the sanitation technology descriptions presented in the Compendium by Tilley et al. (2014). The information provided in these descriptions may also assist the users to provide a more precise score to each particular technology during the 
evaluation criteria stage (as described later in this section).

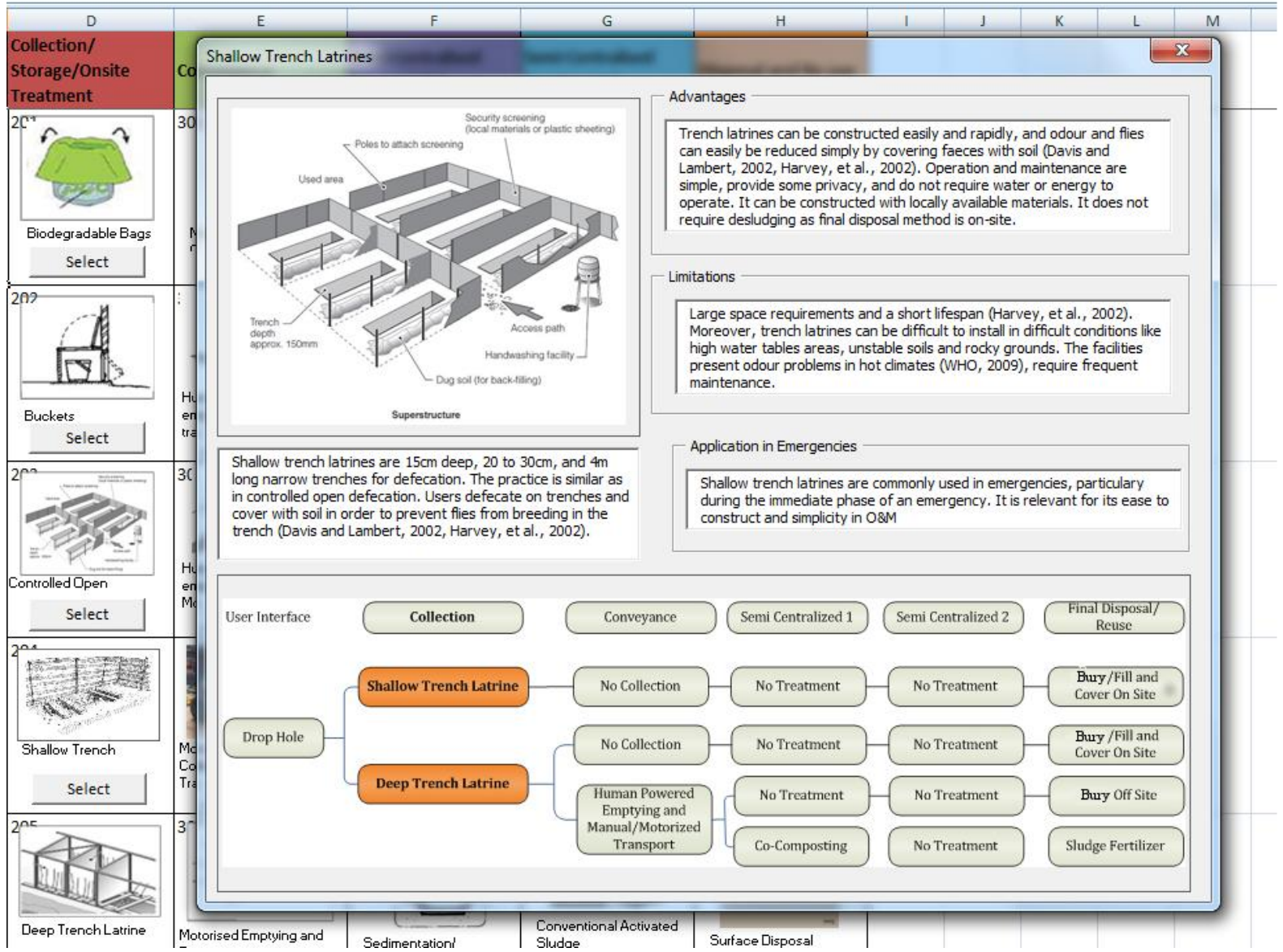

Figure 3 - Example of a technology description - Deep Trench Latrine

\subsection{Screening and Evaluation}

\subsubsection{Screening and Evaluation Criteria}

The factors (criteria) influencing the suitability of the sanitation technologies in the decision-making process were identified and classified as either screening or evaluation criteria as shown in Table 2. Site, technology, and/or socio-cultural related aspects were considered when selecting each individual criterion

Table 2

Criteria for emergency sanitation DSS classified as either screening or evaluation criteria

\section{Screening criteria}

- Remaining infrastructure after disaster

- Water availability to flush

- Land availability for latrines cubicle on-site

- Possibility to excavate

- Groundwater table

- Eventuality of flooding at the latrine site

- Anal cleansing material

- Accessibility by $4 \mathrm{~W}$ vehicle

- Type of waste stream after collection

- Energy availability to power de-sludging, transport and treatment

\section{Evaluation criteria}

- Deploy-ability

- Time to construct or ship

- The use of local material

- Technical complexities or requirement of technical skills

- Sustainability

- Possibility to upgrade

- Life span (before enquiring new one/de-sludging)

- Operation and maintenance ease

- Economical and Environmental Benefit

- Shipping costs 
- Land availability for off-site treatment

- Possibility to excavate at disposal site

- Land application/open dumping environmentally safe and permitted by local authority
○ Construction costs

- Number of people to benefit

- Environmental impact

- Potential for end-product re-use

\subsubsection{Screening stage}

At the screening stage, the 13 screening criteria previously defined and presented in Table 2 are incorporated in the form of questions as described in Figure 4. Multiple choice options are provided for each question in the form. The user needs to select an answer for each of the questions based on the local situation information or given scenarios at the emergency site.

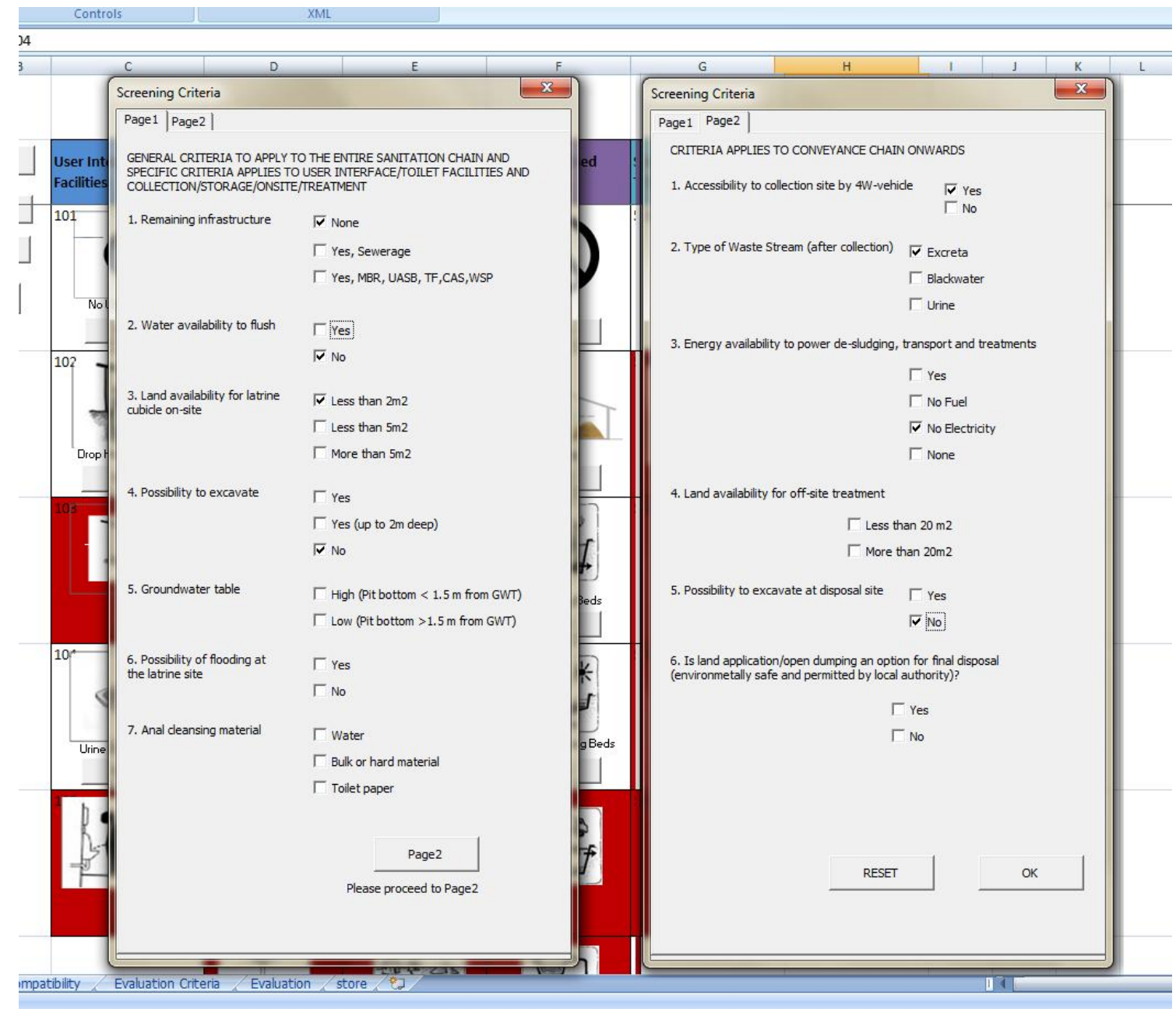

Figure 4 - Screening criteria user form

All the choices have a significant impact on the subsequent selected (or discarded) sanitation technologies; that is, each answer discards one or more sanitation technologies which are not suitable under the given conditions or given scenarios. All the sanitation technology options (both the suitable and unsuitable) are presented in the computer program as an Excel spreadsheet as observed on the right hand side of Figure 5. As observed in Figure 5, the individual steps of the sanitation chain are organized in six sequential columns, and the different individual sanitation technologies are introduced under each individual step of the sanitation chain (column) considering their classification as shown in Table 2. The unsuitable 
options as a result of the screening process are dark red highlighted. The discarded as well as although for visual clarity reasons, the screen capture only shows a fraction of the entire spreadsheet. As an example, if the option "No" is selected on the Question \#2 "Water availability to flush" on the screening criteria form shown in Figure 4 (and also at the left hand side on Figure 5), this selection discards the "Pour Flush" option at the user interface step of the sanitation chain (first column and third row on Figure 5). Subsequently, at the collection step of the sanitation chain (second column on Figure 5) sanitation technologies such as "Septic Tank", "Aerobic Filtration (AF)", "Anaerobic Baffled Reactor (ABR)", "Aqua Privy" and "Urine Diversion Toilet" (not shown in Figure 5) are all discarded since all of them use pour-flush interfaces. In addition, the "Sewerage" option in the "Conveyance" step of the sanitation chain (third column on Figure 5) is also discarded since a sewer does not function without water.

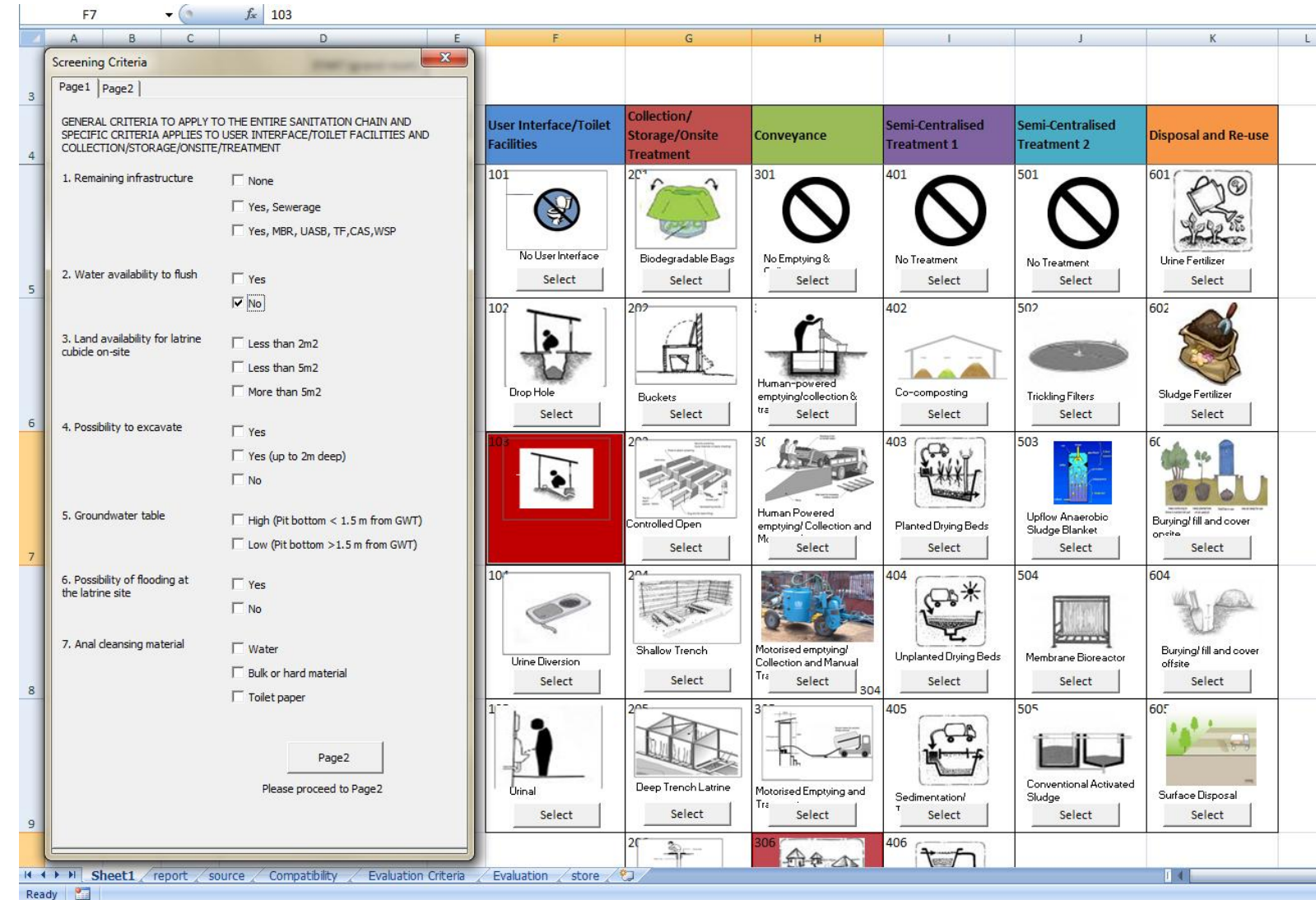

Figure 5 - Screen capture after the screening process (unsuitable sanitation options are highlighted in dark red colour)

The complete list of discarded option in relation to one user input when answering each screening criteria can be observed in

Table 3.

Table 3

Discarded sanitation options upon selecting different choices in screening process

\begin{tabular}{|c|c|c|c|}
\hline Page & Questions & Choices & Discarded Sanitation Options \\
\hline \multirow[t]{5}{*}{1} & \multirow[t]{3}{*}{ 1. Remaining infrastructure } & None & - \\
\hline & & Yes, sewerage & - \\
\hline & & $\begin{array}{l}\text { Yes, MBR, UASB, } \\
\text { TF, CAS, WSP }\end{array}$ & - \\
\hline & \multirow[t]{2}{*}{ 2. Water availability to flush } & Yes & - \\
\hline & & No & (103) Pour flush, (212) Septic tank, (213) \\
\hline
\end{tabular}




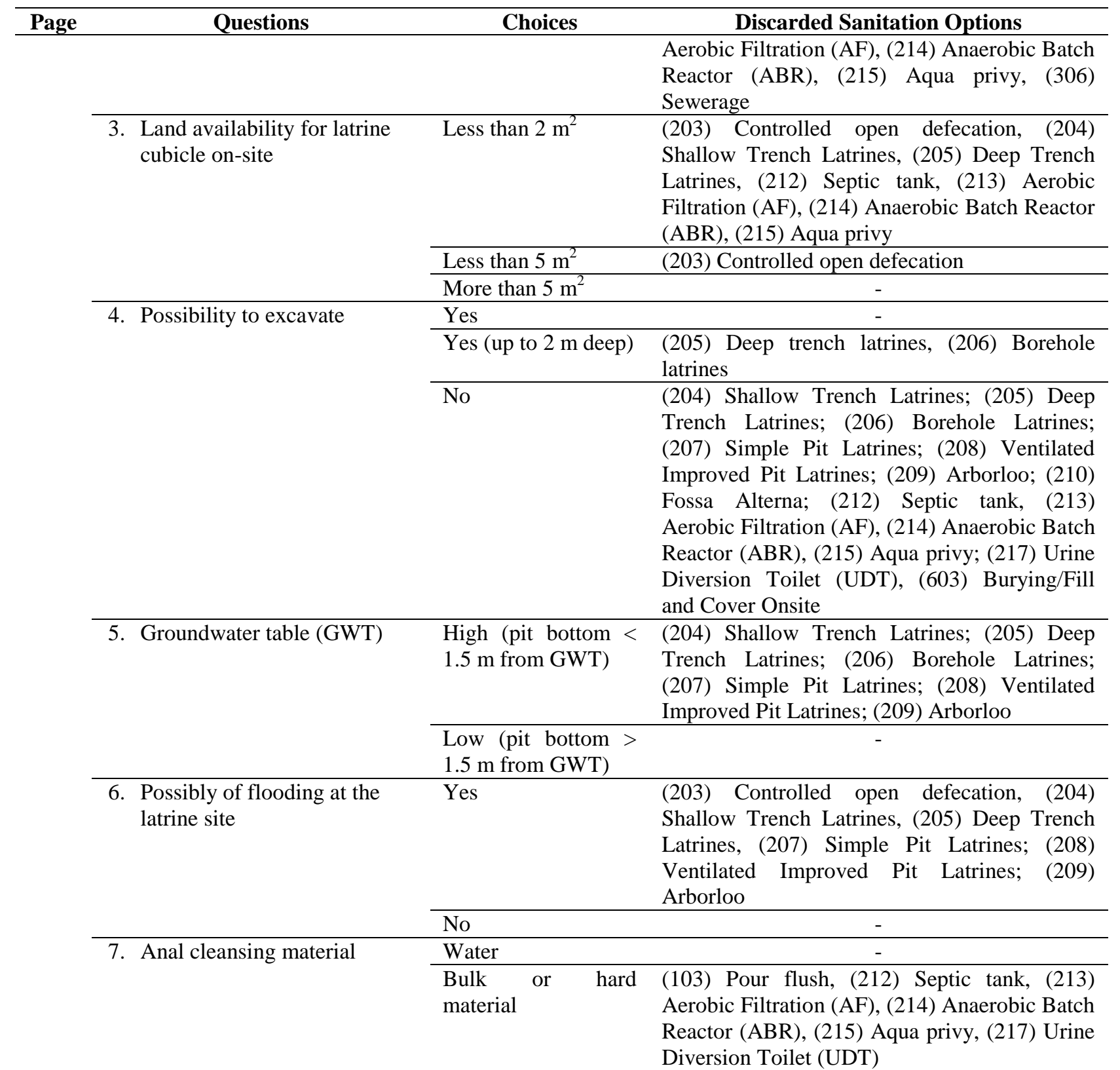

Toilet paper

2 1. Accessibility to collection site Yes by $4 \mathrm{~W}$ vehicle

(303) Human Powered Emptying/Collection and Motorised Transport; (305) Motorised Emptying and Transport

2. Type of waste stream (after Excreta collection)

(105) Urinal ; (220) Urine Jerrycan Storage, (405) Sedimentation/Thickening; (406) Waste Stabilisation Pond (WSP); (407) Surface Flow Constructed Wetlands;(601) Urine fertilizer

Blackwater (105) Urinal ; (220) Urine Jerrycan Storage, (402) Co-composting; (601) Urine fertilizer

Urine (402) Co-composting; (403) Planted Drying Beds; (404) Unplanted Drying Beds; (405) Sedimentation/Thickening; (406) Waste Stabilisation Pond (WSP); (407) Surface Flow Constructed Wetlands; (502) Trickling Filters; (503) Upflow Anaerobic Sludge Blanket (UASB); (504) Membrane Bioreactor (MBR); 


\begin{tabular}{|c|c|c|c|}
\hline Page & Questions & Choices & Discarded Sanitation Options \\
\hline & & & 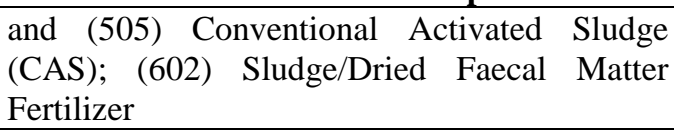 \\
\hline & \multirow{4}{*}{$\begin{array}{l}\text { 3. Energy availability to power } \\
\text { de-sludging, transport and } \\
\text { treatments }\end{array}$} & Yes & - \\
\hline & & No fuel & $\begin{array}{l}\text { (303) Human Powered Emptying/Collection } \\
\text { and Motorised Transport; (304) Motorised } \\
\text { Emptying and Manual Transport; } \\
\text { Motorised Emptying and Transport }\end{array}$ \\
\hline & & No electricity & 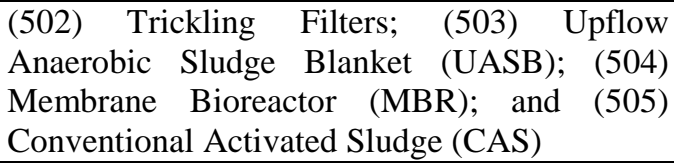 \\
\hline & & None & $\begin{array}{l}\text { (303) Human Powered Emptying/Collection } \\
\text { and Motorised Transport; (304) Motorised } \\
\text { Emptying and Manual Transport; (305) } \\
\text { Motorised Emptying and Transport; (502) } \\
\text { Trickling Filters; (503) Upflow Anaerobic } \\
\text { Sludge Blanket (UASB); (504) Membrane } \\
\text { Bioreactor (MBR); and (505) Conventional } \\
\text { Activated Sludge (CAS) }\end{array}$ \\
\hline & \multirow[t]{2}{*}{$\begin{array}{l}\text { 4. Land availability for off-site } \\
\text { treatment }\end{array}$} & Less than $20 \mathrm{~m}^{2}$ & $\begin{array}{l}\text { (402) Co-composting; (403) Planted Drying } \\
\text { Beds; (404) Unplanted Drying Beds; (405) } \\
\text { Sedimentation/Thickening; (406) Waste } \\
\text { Stabilisation Pond (WSP); (407) Surface Flow } \\
\text { Constructed Wetlands; (505) Conventional } \\
\text { Activated Sludge (CAS) }\end{array}$ \\
\hline & & More than $20 \mathrm{~m}^{2}$ & - \\
\hline & \multirow{2}{*}{$\begin{array}{l}\text { 5. Possibility to excavate at } \\
\text { disposal site }\end{array}$} & Yes & - \\
\hline & & No & (604) Burying/Fill Cover Offsite \\
\hline & \multirow{2}{*}{$\begin{array}{l}\text { 6. Is land application/open } \\
\text { dumping an option for final } \\
\text { disposal (environmentally } \\
\text { safe and permitted by local } \\
\text { authority)? }\end{array}$} & Yes & - \\
\hline & & No & (605) Surface Disposal/Open Dumping \\
\hline
\end{tabular}

\subsubsection{Chain Compatibility}

After the screening process is finalized, a feasible sanitation chain needs to be selected by choosing one of the remaining (available) sanitation technology options for each step (column) of the sanitation chain. Once a sanitation technology option is chosen (for each step, regardless the order), the computer program runs a compatibility verification test using preloaded information in the form of a compatibility matrix. The computer program automatically discards any incompatible options in response to selection of an option.

The compatibility matrix is built based on the feasible combination of sanitation technologies for a defined sanitation chain. The compatibility is assessed considering how each sanitation option from a specific step of the sanitation chain affects the selection of other sanitation options from other steps of the sanitation chain. As an example, (as shown in Figure 6) if the sanitation option "biodegradable bags" is selected in the collection step of the sanitation chain, automatically the computer program determines the compatible sanitation options for the other steps of the sanitation chain and discards all the sanitation options that are not feasible. That is, it would be feasible to have a biodegradable bag option at the collection step of the sanitation chain without the need of having a collection system at the conveyance step of the sanitation chain (first option shown at the very top of Figure 6). Consequently, this option leads to an on-site disposal (i.e., bury on-site). Analyzing the second example provided at the bottom of Figure 6 (raised latrines), it is observed that when the sanitation option "raised latrines" is selected at the collection step of the sanitation chain, a 
collection system (or a tank-emptying option) needs to be incorporated in the conveyance step of the sanitation chain to make the entire chain feasible. The feasible sanitation chain pathways for all the listed sanitation technologies were determined in flow charts similar to the one presented in Figure 6.

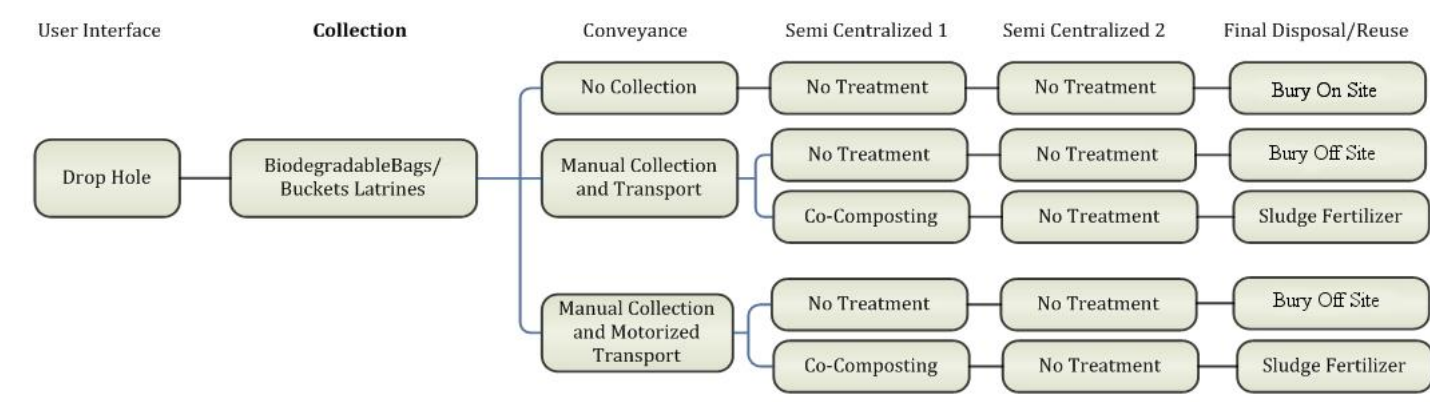

Biodegradable Bags and Bucket Latrines System
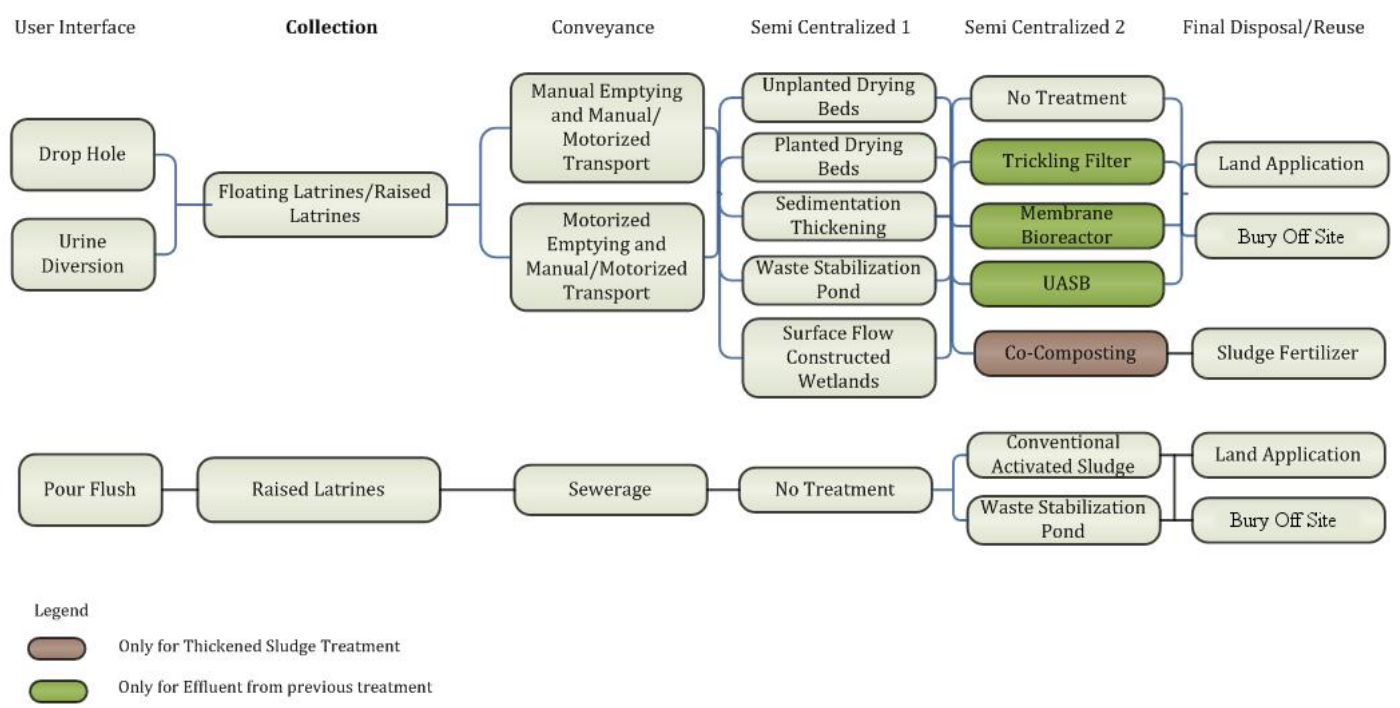

Raised Latrines and Floating Latrines System

Figure 6 - Potential chain options when considering "Biodegradable/Bucket System" (Top) and "Raised Latrine and Floating Latrines System" (Bottom) at the collection step of the sanitation chain.

All the feasible sanitation chain pathways for each single sanitation technology were translated into a binary coded matrix, used as input to the DSS program. When a certain sanitation technology is selected, the computer program automatically verifies the compatibility using that binary code matrix. Subsequently, the computer program discards all the incompatible options.

Figure 7 shows a screen capture of the computer program (Excel spreadsheet) after the screening and the chain compatibility verification processes are completed. The options that were discarded as a consequence of the screening process are dark red highlighted, while incompatible options (after going through the compatibility verification process) are light red highlighted. The highlighted sanitation options can no longer be selected. Figure 7 shows a continuation of the same example started when describing the screening stage. For that example, due to the unavailability of water (decided at the screening phase), the "Pour Flush" sanitation option was excluded (dark red highlighted) at the user interface step of the sanitation chain. Subsequently, if the "Biodegradable Bag" sanitation technology is selected at the "Collection" step of the sanitation chain (second column of Figure 7), the rest of the sanitation technologies under the same step "Collection" of the sanitation chain are discarded (light red highlighted). In addition, other incompatible sanitation technologies such as the 
"Urine Diversion" at the step "User Interface" of the sanitation chain, as well as the

Figure 7 - Compatibility verification process

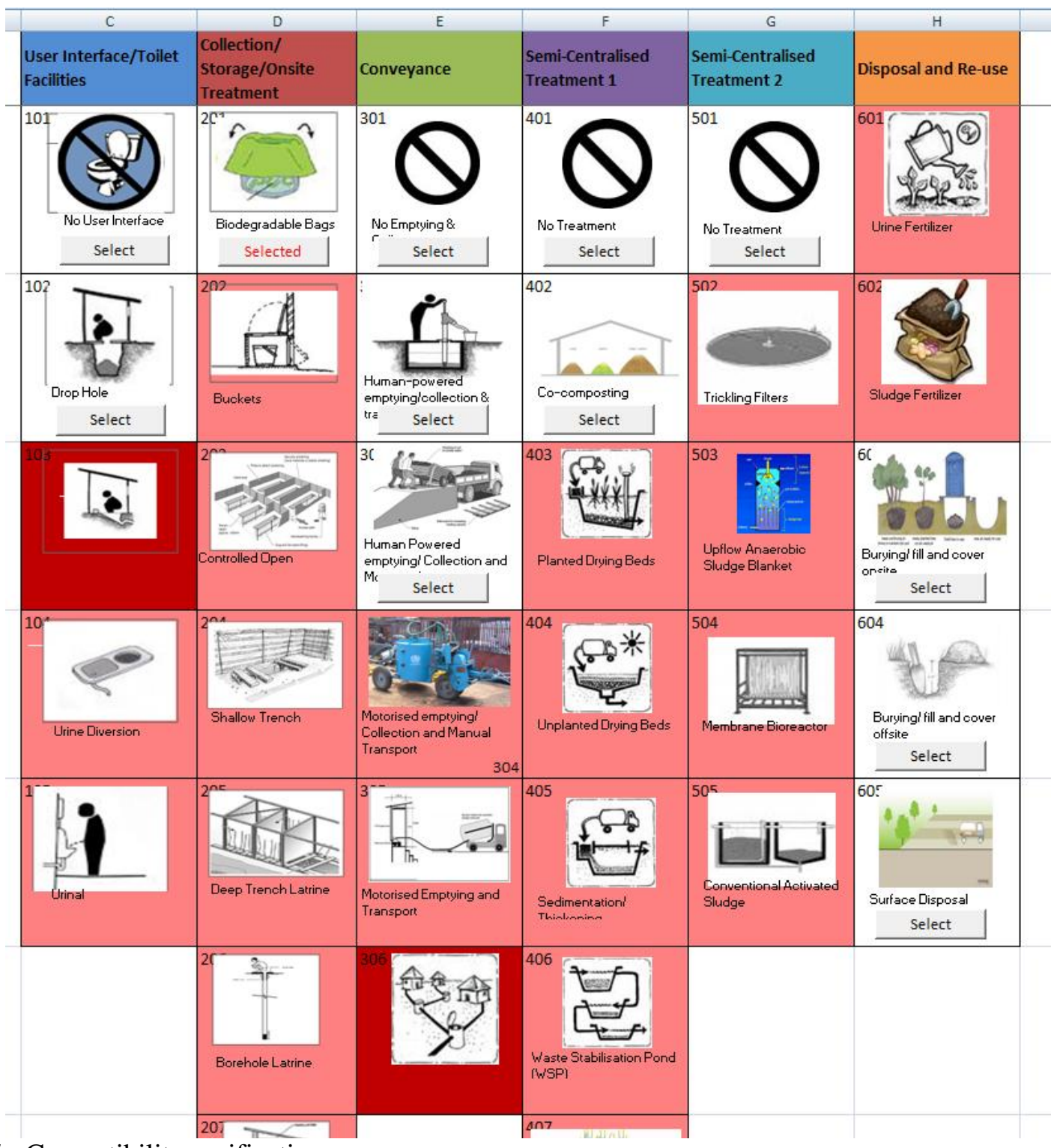

Afterwards, the selection of the sanitation alternatives can be finalized by selecting the remaining sanitation technologies for the rest of the steps (columns) of the sanitation chain. Selected sanitation chains consisting of six different individual sanitation technologies can be created as shown in Figure 8 below.

Different chains can be implemented at the same site should they compliment and serve different waste stream or different group of users. For example the DSS users might decide to use UD system, thus need to plan for different conveyance-treatment and disposal of urine and excreta. They might also decide to provide a biodegradable-bags-system to serve the elderly and people with special need that reside in parts of one emergency settlement 


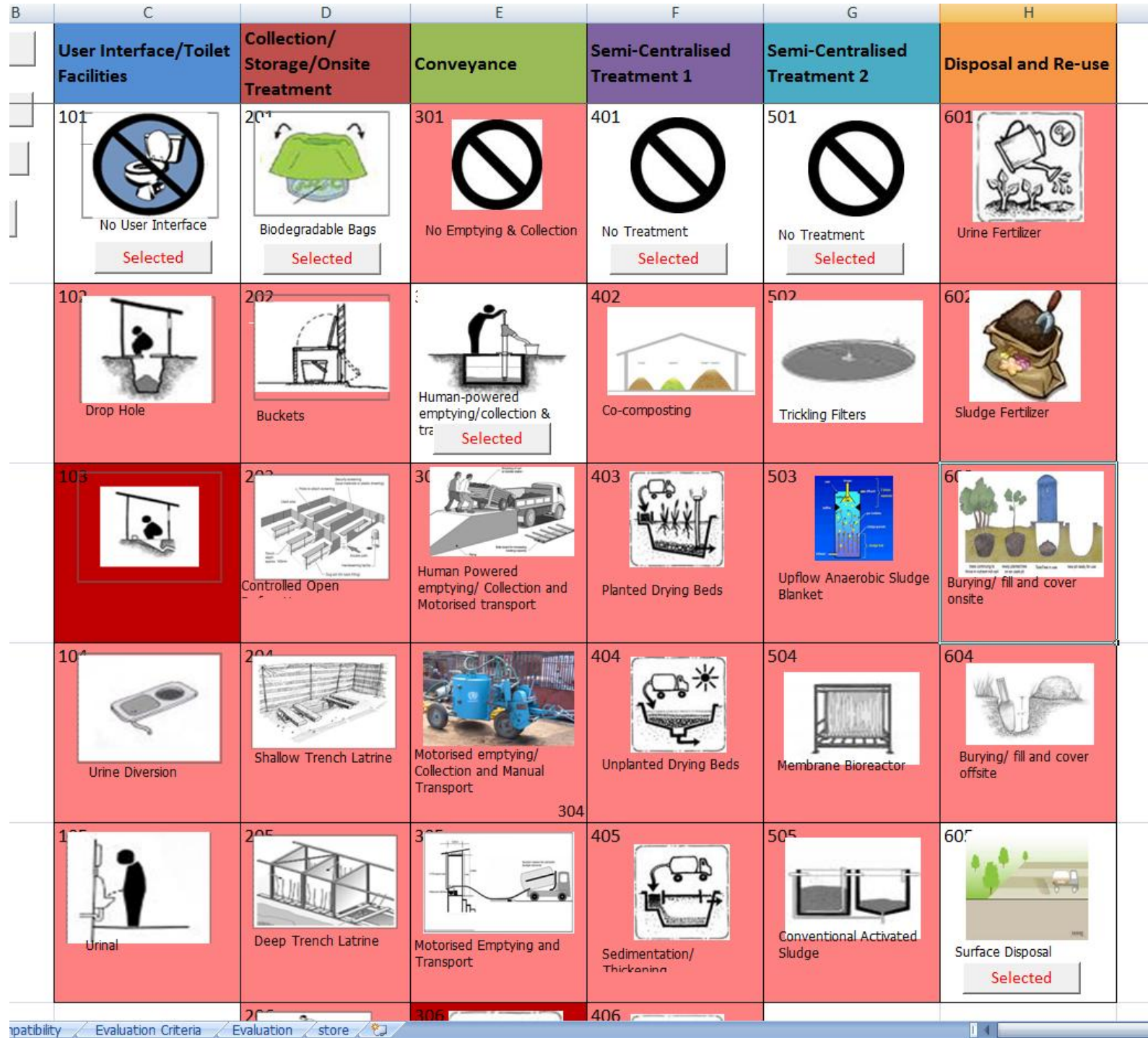

Figure 8. Selected sanitation chain after completing the screening and compatibility verification processes

\subsubsection{Evaluation stage}

The selected sanitation chain can be then evaluated by applying predefined evaluation criteria. As previously described in Table 2, the evaluation criteria are grouped into three categories i.e. deploy-ability, sustainability, and economical and environmental benefit. At this evaluation step each single sanitation technology describing the selected sanitation chain needs to be scored. The scoring system ranges from "0" to "5" indicating how well each specific sanitation technology meets the predefined criteria. A complete description with the scoring criteria is presented in Table 4. The DSS calculates the final (total) score for each evaluated sanitation chain.

The grouping of evaluation criteria into three categories is attributed to the many contributing factors in evaluating one sanitation technology. These factors often share the same objectives that they can be grouped into one criterion. The grouping of these aspects would enhance the practicality where there would not be too many criteria to be scored individually. Thus it maintains the DSS' aim of being user-friendly, where the users' are given sufficient dose of scoring responsibility. 
Table 4

Scoring Guide for the Evaluation Criteria

Figure 9 shows two scoring examples (scoring capture screens on the computer based DSS) applied to the sanitation chain described in Figure 8 (top of Figure 9), as well as to the sanitation chain example with the raised latrine component described in Figure 6 (bottom of Figure 9). Some conflicting issues may arise when scoring the sanitation technologies of the chain as follows. As an example, three main aspects need to be simultaneously considered (as described in Table 4) when scoring the "Deployability" evaluation criterion including time, the use of local material, and the need for special equipment and technical skills. Some contradictory information for the same sanitation technology may add complexity to the scoring process. For instance, a certain sanitation technology may be deployable in a long period of time (low score), uses mostly local material (high score), and has a low requirement on equipment and technical skills (high score); therefore, priority should be given to the particular aspect that influences the selection the most. That is, for this particular example either the time, or the usage of local material, or the requirement of equipment and technical skill needs to be prioritized. The priority needs to be consistent throughout other options when scoring the same category, also when scoring the next sets of sanitation chains, so that the scores are all comparable. 


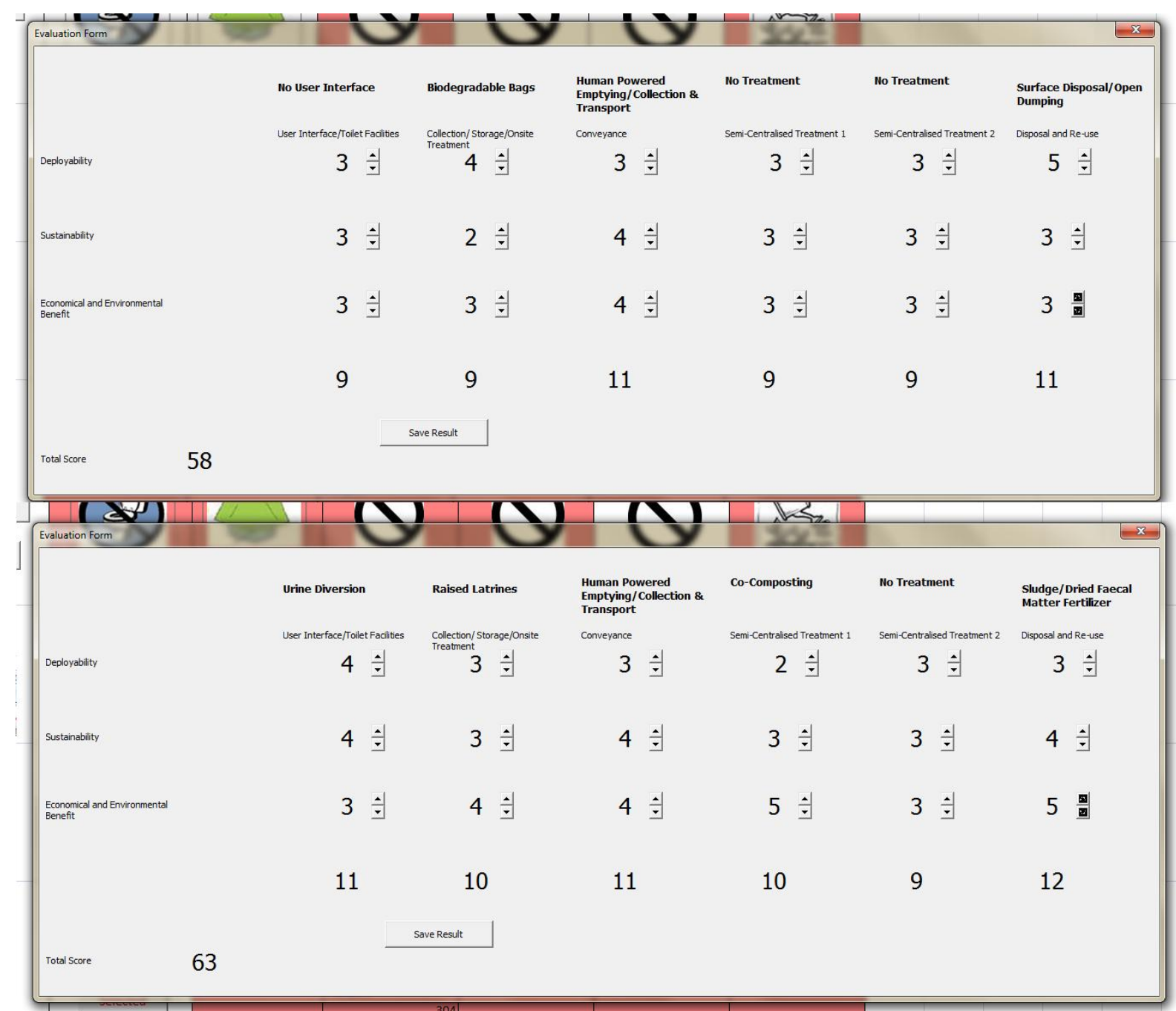

Figure 9. A scoring example for the evaluation stage is provided. Top: evaluation stage scoring for the biodegradable bags system example covered in Figure 8; and Bottom: Evaluation stage scoring for the raised latrine system example shown in Figure 6.

The results of every single selected and evaluated sanitation chain can be saved, and the complete evaluation process can be restarted from the very beginning selecting a completely different and new sanitation chain. After evaluating all desired sanitation chains, a final report can be generated. The final report compares all the selected sanitation chains (including their final scores) as shown in Figure 10. Up to 20 different sanitation chains can be compared in the same report.

The final report shown in Figure 10 compares two feasible sanitation chains as previously discussed. One chain is provided with a biodegradable-bag at the collection step of the sanitation chain, while the other chain is provided with a raised latrines system. The computer-based DSS concluded that first sanitation chain (biodegradable bag) does not require a toilet structure; that is, no user interface is needed. The used bags can be collected using manual collection and transportation, and can be disposed in selected disposal sites without the need for treatment. The second sanitation chain (raised latrines) is provided with a urine-diversion user interface dividing the waste streams into urine and excreta. The excreta (collected in a collection tank) can be regularly emptied using manual emptying and transportation equipment. Then, the collected excreta can be composted at a composting facility, and the resulting product can be used as a fertilizer. The final score obtained for the biodegradable-bag and for the raised-latrine chains was of 58 and 63, respectively. That is, the raised-latrine chain can be considered a better sanitation alternative than the biodegradable 
bag chain. For this particular examples (referring back to the evaluation scores described in evaluation criteria (mainly due to the composting and reuse of the excreta as a fertilizer).

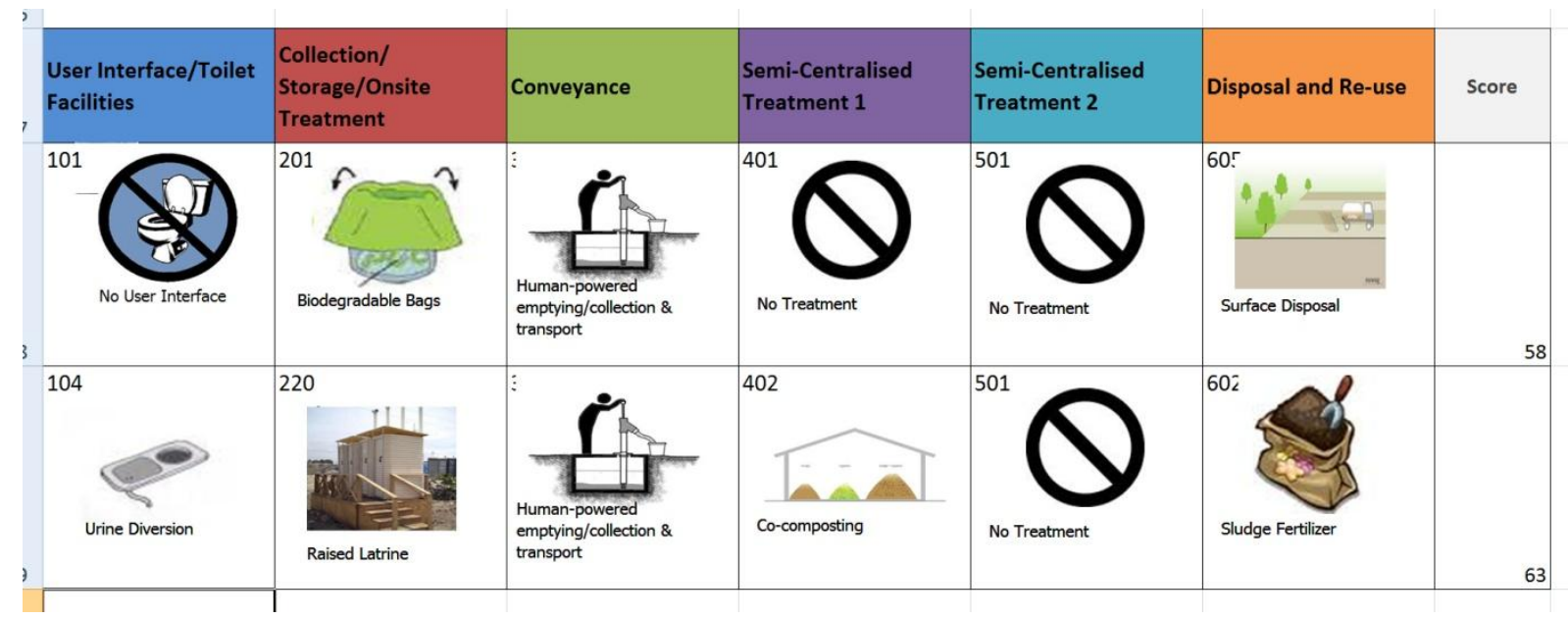

Figure 10. Example of a final report following showing the final evaluation for the sanitation chains previously discussed and evaluated in Figure 9.

The evaluation stage is subject to the DSS user consideration towards certain technologies. The score for one technology may significantly differ when scored by different users. Nevertheless, the provision of both a clear description of the evaluation criteria, as well as a scoring guidance may help users to score the different technologies as accurately as possible. In addition, it is recommended to conduct collective scoring by a team, rather than by individuals to achieve a more objective and proportional scoring.

The final report is the output of the DSS. The final report aims at comparing the advantages and limitations of potential sanitation alternatives by means of quantifying the advantages and limitations with certain scoring system. This comparison may provide users with an elaborated and systematic approach to select the most suitable sanitation alternatives to the given scenarios.

\subsection{Preliminary system validation}

In order to verify the applicability of the developed DSS, the program was applied to evaluate the sanitation provision in Haiti after the emergency situation caused by the massive earthquake in 2010. Information for identifying local or site specific conditions was taken from several reports and papers (Bastable and Lamb, 2012; Patel et al., 2011; Reed, 2010). The identified site-specific constraints in Haiti include unavailability of space for latrines at the displacement settlements, limited space for treatment and disposal, non possibility to excavate, and no availability of water to flush.

The site-specific conditions at the emergency situation were introduced at the screening stage of the DSS. The screening stage discarded several unsuitable sanitation technologies; the following sanitation technologies were found suitable: (i) no user interface, drop hole, and urine diversion (at the "User Interface" step of the sanitation chain); (ii) biodegradable-bags/bucket latrines, porta-preta, floating latrines, raised latrines, and chemical toilets (at the "Collection" step); (iii) all the sanitation technologies options except Sewerage (at the "Conveyance" step); (iv) No Treatment, Co-composting, and planted and unplanted drying beds (at the "Semi Centralized Treatment 1" step); (v) only the No Treatment option (at the "Semi Centralized Treatment 2 step"); and (vi) Sludge Fertilizer and Surface Disposal (at the "Disposal and Reuse" step). 
The DSS was able to narrow down all the available sanitation technologies suggesting discussed in the Introduction Section, all the screened sanitation technologies were actually in use in the Haiti emergency. Therefore, the DSS yields similar results regarding potential sanitation technologies that can be applied compared to those actually applied by the relief agencies at the emergency site. However, the DSS goes one step further by both suggesting a sanitation chain rather than a single sanitation technology, and by also evaluating and ranking (by scoring all the sanitation technologies in a chain) the feasible resulting sanitation chains.

After the screening stage is finalized several sanitation chains can be proposed. For this particular case, since the relief agencies do not normally want to deal with the maintenance of sanitation facilities, the sanitation technology "No Emptying \& Collection" at the "Conveyance" step of the sanitation chain was initially selected. However, the compatibility verification test discarded all the possible sanitation options at the "Disposal and Reuse" step of the sanitation chain, yielding no feasible sanitation chains as observed in Figure 11. Therefore, another option was needed to be selected including a different sanitation technology at the "Conveyance" step of the sanitation chain; that is, it would not be possible to skip some sort of maintenance of the collection facilities by the relief agencies.

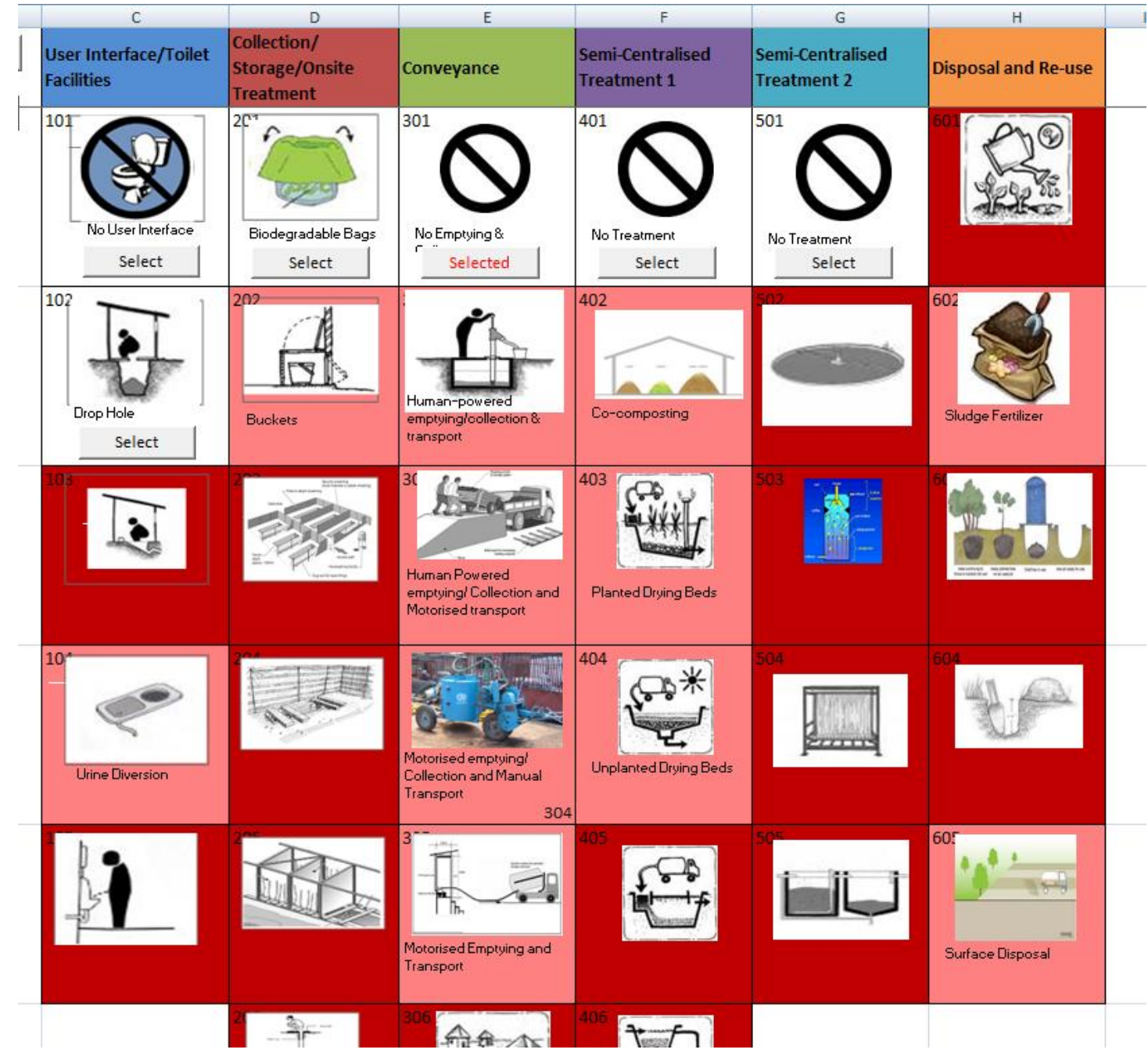

Figure 11. Screen capture of the DSS when the "No-Emptying \& Collection" option is selected at the "conveyance" step of the sanitation chain.

Subsequently, the "Human-powered emptying \& collection" sanitation technology was selected at the "Conveyance" step of the sanitation chain. After the program ran the 
compatibility verification test, the rest of the feasible options for the sanitation chain were selected. The selected sanitation chain was identical to the sanitation chain presented in Figure 8 (i.e., the sanitation chain with the biodegradable-bags sanitation technology at the "Collection" step of the sanitation chain). This chain was already evaluated as shown in Figure 9, and presented in the final evaluation report in Figure 10.

The DSS indeed went one step further than the relief agencies decision at the emergency site, and provided an entire sanitation chain consisting of several compatible sanitation technologies properly evaluated. One of the key design features of the present DSS is the consideration of the entire sanitation chain for the sanitation services to be provided and not just the provision of toilets (collection step of the chain). As was discussed in the introduction of this study, one of the main critical issues with the sanitation technologies provided at the emergency situation in Haiti by the relief agencies was not considering any "Conveyance" and/or "Disposal and Re-use" technologies for the sanitation services provided at the camps. These issues are properly considered by the developed DSS.

\section{Conclusions}

The following conclusions can be drawn from this study:

- A computer-based decision support system (DSS) is a useful tool for selecting suitable sanitation alternatives to be provided in the realm of emergencies when an accurate decision has to be made in the shortest possible time.

- The development of a DSS as a computer program incorporating the sanitation chain approach provides several advantages from the users' point of view compared to previously developed DSSs.

- The developed computer-based DSS addresses several deficiencies commonly encountered in existing DSS such as the application of standard practices and intuition, the consideration of the local conditions commonly found in emergency settings, the limited knowledge exhibited by emergency planners, and the consideration that a proper sanitation provision should exceed the provision of only a collection technology (that is, beyond the provision of toilets).

- The DSS can be easily run providing up to 20 feasible sanitation options ranked in a logical order (from the most suitable to the least suitable) in a short period of time.

- The DSS is designed as a flexible program that can easily be modified. That is, more or different sanitation technologies can be added, the compatibility matrix can be modified to satisfy emergency planner's special needs, and both the screening and evaluation criteria can be changed. In addition, the computer-based DSS is flexible considering that each different user can introduce his or her own inputs depending on personal evaluation of the particular situation.

- The final decision regarding the provision of the most appropriate sanitation alternative entirely depends on the user. The DSS is thought to be a resource to help on the decision-making process.

- Considering the preliminary validation on the Haiti's past emergency situation, it can be concluded that the DSS provides realistic results. 
The DSS is considered a valuable tool for selecting appropriate sanitation services addressing challenging emergency sanitations. Further research is needed to completely validate this tool using data either from past or current emergencies including information related to emergency preparatory activities.

\section{Acknowledgement}

The DSS is developed under the project 'Stimulating local innovation on sanitation for the urban poor in sub-Saharan Africa and South-East Asia' financed by Bill \& Melinda Gates Foundation.

\section{References}

Akvo.org, WASTE. The Sanitation Decision Support Tool. Akvo.org, WASTE, 2012.

Bastable A, Lamb J. Innovative designs and approaches in sanitation when responding to challenging and complex humanitarian contexts in urban areas. Waterlines 2012; 31: 67-82.

Burnham G, Saade A. Water, sanitation and hygiene in emergencies. In: Burnham G, Saade A, editors. Public health guide for emergencies. International Federation of Red Cross and Red Crescent Societies ; Johns Hopkins School of Hygiene and Public Health, [Geneva]; [Baltimore, Md.], 2004.

Buuren Jv. SANitation CHoice Involving Stakeholders: a participatory multi-criteria method for drainage and sanitation system selection in developing cities applied in Ho Chi Minh City, Vietnam. Wageningen university 2010.

Castellano D, de Bruijne G, Maessen S, Mels A. Modelling Chaos? Sanitation Options; Support and Communication Tool. Water Practice and Technology 2011; 6.

Fenner RA, Guthrie PM, Piano E. Process selection for sanitation systems and wastewater treatment in refugee camps during disaster-relief situations. Water and Environment Journal 2007; 21: 252264.

Finney B, Gerheart R. A User's Manual for WAWTTAR. Environmental Resources Engineering, Humboldt State University 1998: 70.

Garfi M, Ferrer-Marti L. Decision-making criteria and indicators for water and sanitation projects in developing countries. Water Science \& Technology 2011; 64: 83-101.

Harvey P, Baghri S, Reed B, Water E, Development C. Emergency sanitation : assessment and programme design. Loughborough: WEDC, 2002.

Harvey P, Water E, Development C. Excreta disposal in emergencies : a field manual. [Loughborough]: Water, Engineering and Development Centre, 2007.

Johannessen A, Patinet J, Carter W, Lamb J. Sustainable sanitation for emergencies and reconstruction situations. Factsheet of Working Group 8. Sustainable Sanitation Alliance (SuSanA), 2012.

Katukiza AY, Ronteltap M, Oleja A, Niwagaba CB, Kansiime F, Lens PNL. Selection of sustainable sanitation technologies for urban slums - A case of Bwaise III in Kampala, Uganda. Science of The Total Environment 2010; 409: 52-62.

Loetscher T, Keller J. A decision support system for selecting sanitation systems in developing countries. Socio-Economic Planning Sciences 2002; 36: 267-290.

Manilla Arroyo D. Blurred lines: accountability and responsibility in post-earthquake Haiti. Medicine, Conflict and Survival 2014; 30: 110-132.

Mara D, Drangert J, Anh NV, Tonderski A, Gulyas H, Tonderski K. Selection of sustainable sanitation arrangements. Water Policy 2007; 9: 305.

Maurer M, Bufardi A, Tilley E, Zurbrügg C, Truffer B. A compatibility-based procedure designed to generate potential sanitation system alternatives. Journal of Environmental Management 2012; 104: 51-61.

Palaniappan M, Lang M, Gleick PH, Pacific I. A review of decision-making support tools in the water, sanitation, and hygiene sector. Pacific Institute, Oakland, Calif., 2008.

Patel D, Brooks N, Bastable A. Excreta disposal in emergencies: Bag and Peepoo trials with internally 
displaced people in Port-au-Prince. Waterlines 2011; 30: 61-77.

Reed B. Emergency Excreta Disposal Standards and Options for Haiti. In: Henrys I, Harvey B, editors. DINEPA; Global WASH Cluster, 2010.

Sah L, Rosseau DPL, Van Der Steen P. Selection tool for natural wastewater treatment systems. SWITCH Document. SWITCH, 2010.

Sparkman D. More than just counting toilets: The complexities of monitoring for sustainability in sanitation. Waterlines 2012; 31:260-271.

Sphere P. Humanitarian charter and minimum standards in disaster response. The Sphere Project, Geneva, Switzerland, 2004.

Tilley E, Supply W, Council SC. Compendium of sanitation systems and technologies: Eawag Dübendorf, Switzerland, 2008.

Tilley E, Zurbrügg C, Lüthi C. A flowstream approach for sustainable sanitation systems. Social Perspectives on the Sanitation Challenge. Springer, 2010, pp. 69-86.

Tilley EA, Ulrich L, Lüthi C, Reymond P, Zurbrügg C. Compendium of sanitation systems and technologies. Swiss Federal Institute of Aquatic Science and Technology ; Water Supply and Sanitation Collaborative Council, Dübendorf, Switzerland; Geneva, Switzerland, 2014.

UNHCR. Handbook for emergencies. Geneva: UNHCR, 1999.

van Dijk MP. Sanitation in Developing Countries: Innovative Solutions in a Value Chain Framework, 2012.

Verhagen J, Ryan P. Sanitation Services for the Urban Poor: Symposium Background Paper. IRC Symposium: Sanitation for The Urban Poor - Partnership and Governance, Delft, The Netherlands, 2008.

Wirmer B. A functional approach to guide sustainable innovations in the sanitation chain. Innovation Sciences. Master of Science. Eindhoven University of Technology, Utrecht, 2014.

Wisner BAJWHO. Sanitation. Environmental health in emergencies and disasters a practical guide. World Health Organization, Geneva, 2002, pp. 127-147. 